2 Aman Dhuwe ${ }^{\mathrm{a}}$, Jason Lee ${ }^{\mathrm{a}}$, Stephen Cummings ${ }^{\mathrm{a}}$, Eric Beckman ${ }^{\mathrm{a}}$, Robert Enick ${ }^{\mathrm{a}, \mathrm{b}, *}$

3 a Department of Chemical and Petroleum Engineering, Swanson School of Engineering,

4 University of Pittsburgh, Pittsburgh, PA 15261, USA

5 b ORISE Faculty Fellow, National Energy Technology Laboratory, Office of Research and

6 Development, U.S. Department of Energy, Pittsburgh, PA 15236, USA

7 * Corresponding Author: Dr. Robert Enick (rme@ pitt.edu)

8 Department of Chemical and Petroleum Engineering, Swanson School of Engineering, 940

9 Benedum Engineering Hall, 3700 O'Hara Street, University of Pittsburgh, Pittsburgh PA 15261

10 Tel: +1 412624 9649, Fax: +1 4126249639

\title{
11 Abstract
}

12 The abilities of three classes of low molecular weight, metal-based, associative compounds to 13 thicken high pressure ethane, propane or butane have been assessed with a close clearance falling

14 ball viscometer. Tributyltin fluoride (TBTF) does not require a heating/cooling cycle to attain 15 dissolution, and at a concentration of $1 \mathrm{wt} \%$ in ethane, propane or butane yields $70-100$-fold 16 viscosity increases at $25^{\circ} \mathrm{C}$. Increasing temperature substantially reduces TBTF's thickening 17 ability. Although hydroxyaluminum di-2-ethylhexanoate (HAD2EH) is insoluble in ethane, it 18 does dissolve in liquid propane or butane after mixing at $\sim 100^{\circ} \mathrm{C}$ and cooling to temperatures as 19 low as $40^{\circ} \mathrm{C}$. HAD2EH induces small viscosity increases in propane, but is a very effective

20 butane thickener. Increasing temperature causes a relatively small decrease in HAD2EH's 21 thickening performance. Combining a phosphate ester and a crosslinker in ethane, propane or 
22 butane yields a translucent liquid with viscosity increases that are significantly less than those 23 attained with TBTF or HAD2EH.

24 Keywords: Ethane, propane, butane, small molecule thickener, association, viscosity

\section{1. Introduction}

26 According to a recent survey published by the Oil \& Gas Journal in 2014 [1], hydrocarbon

27 miscible enhanced oil recovery (EOR) has contributed about $1.5 \%$ of overall oil production in

28 the US over the past several decades. Hydrocarbon miscible flooding typically involves the

29 injection of natural gas liquids (NGL) [2], a mixture composed primarily of ethane, propane,

30 butane and a small amount of heavier alkanes. This NGL mixture is an excellent solvent for the

31 displacement of oil because it usually exhibits first contact miscibility (i.e. complete miscibility)

32 with crude oil.

33 Hydrocarbon miscible EOR is not as pervasive in the United States as $\mathrm{CO}_{2}$ EOR because most of

34 the $\mathrm{CO}_{2}$ employed is conveniently obtained from massive natural deposits and is transported 35 through an existing $\mathrm{CO}_{2}$ distribution pipeline network, whereas the NGLs used for EOR 36 originate in gas processing plants associated with oil recovery projects (including $\mathrm{CO}_{2} \mathrm{EOR}$ ).

37 Further, there are clearly markets for NGL other than use as an oil recovery solvent; it may be 38 sold for its fuel value (e.g. LPG blends of propane and butane) or for the use as a raw material in 39 the manufacture of chemicals (e.g. cracking ethane to make ethylene). Nonetheless, when there 40 are no nearby markets for NGL, it can be economic to use these stranded fluids for hydrocarbon 41 miscible EOR. It is also possible to employ blends of NGL with $\mathrm{CO}_{2}$ or methane for EOR, 42 especially because larger supplies of $\mathrm{CO}_{2}$ or methane may be readily available and significantly 43 less expensive than the NGL themselves. $\mathrm{CO}_{2}$ is a less miscible with crude oil than NGL while 
44 methane is a very poor oil solvent, therefore the addition of these gases to NGL can lead to

45 higher miscibility pressures or an immiscible gas displacement process.

46 Although the solvent strength of NGL for crude oil is exemplary, they have the same two

47 fundamental disadvantages as $\mathrm{CO}_{2}$; low density and viscosity relative to crude oil. At

48 hydrocarbon miscible EOR conditions (i.e. $\mathrm{T}=25-120^{\circ} \mathrm{C}$ and $\mathrm{P}=3-20 \mathrm{MPa}$ ) ethane, propane

49 and butane exhibit density values of roughly $0.4 \mathrm{~g} / \mathrm{cm}^{3}, 0.5 \mathrm{~g} / \mathrm{cm}^{3}$ and $0.6 \mathrm{~g} / \mathrm{cm}^{3}$ respectively $[1$,

50 3-5]. Because NGL densities are lower than that of crude oil, NGL will exhibit gravity override

51 as they flow through the formation, reducing oil recovery in the lower portions of reservoir.

52 Unfortunately, it is currently not possible to substantially increase the density of NGL with a

53 dilute concentration of an additive.

54 The viscosity of NGL at reservoir conditions is roughly $0.1 \mathrm{mPa}$, significantly lower than that

55 of brine and oil. The range of crude oil viscosity values associated with hydrocarbon miscible

56 projects in the US is $1-140 \mathrm{mPa} \mathrm{s}(1 \mathrm{mPa} \mathrm{s}=1 \mathrm{cP})$, while in Canada crude oil viscosity values

57 in hydrocarbon miscible projects range between $0.1-0.8 \mathrm{mPa} \mathrm{s}$ [1]. The low viscosity of NGL

58 relative to the crude oil being displaced leads to an unfavorable mobility ratio which, in turn,

59 results in viscous fingering, poor sweep efficiency, and disappointingly low oil recovery.

60 Further, in stratified formations, the viscosity contrast enhances the flow of NGL into thief zones

61 where little to no oil resides. It is possible to diminish the mobility of dense NGL by reducing

62 their relative permeability via a water-alternating gas (WAG) injection process. The objective of

63 this study, however, is to determine if one can reduce NGL mobility by increasing the viscosity

64 of NGL using dilute concentrations of small associating compounds. To be effective, small

65 molecule NGL thickeners should dissolve completely in these high pressure fluids, preferably

66 forming a transparent, thermodynamically stable, single-phase solution capable of flowing 
67 through porous media. Ideally, dissolution and viscosity enhancement can be attained without

68 the need for a two-step process of high pressure heating (which disrupts intermolecular 69 associations) and cooling (which allows the viscosity-enhancing associating network to be 70 established). If the viscosity of NGL solution can be tailored to match that of the crude oil,

71 dramatic improvements in mobility control could result and the need to implement the WAG 72 process would be eliminated.

73 There is a second, distinct, petroleum-related technology that could benefit from an NGL

74 thickener. NGL can serve as dry hydraulic fracturing fluid in low permeability formations that 75 contain crude oil and/or natural gas and are water-sensitive (i.e. the use of water for fracking 76 causes the permeability of the faces of the fractured rock to decrease). NGL is an excellent 77 alternative solvent for such formations. However the extremely low viscosities of these high 78 pressure liquids results in relatively small fractures and difficulties in transporting high 79 concentrations of proppant particles (usually sand) into the fracture.

80 Previous work on use of small-molecule thickeners for NGL have focused on trialkyltin

81 fluorides, hydroxy-aluminum surfactants, and mixtures of phosphorous esters and multi-valent

82 metals ions [6-9]. In each case, inter-molecular associations are employed to create non-covalent

83 associations in solution, which then increase viscosity substantially.

\section{$84 \quad 1.1 \quad$ Trialkyltin fluorides}

85 Trialkyltin fluorides typically dissolve in organic liquids after several minutes of stirring. 86 Although heating during the mixing process hastens dissolution, a heating/cooling cycle is not 87 required to attain dissolution of viscosity enhancement. 
88 Tri-n-butyl tin fluoride (TBTF), a white powder with a melting point of $271^{\circ} \mathrm{C}$, is an extremely 89 effective thickener for light alkanes. Dunn and Oldfield [10] first reported that TBTF increases 90 the viscosity of non-polar liquid solvents such as n-pentane and carbon tetrachloride. Trialkyltin 91 fluorides are thought to form long linear transient polymeric chains via intermolecular 92 associations between the electropositive tin atom and the electronegative fluorine atom of a 93 neighboring molecule, with the three alkyl chains enhancing solubility in the hydrocarbon 94 solvent and a low enough level of steric hindrance so as to not disrupt the tin-fluorine 95 associations [10], as shown in Fig. 1. Heller and co-workers found that TBTF significantly 96 increases the viscosity of high pressure propane and butane [6]. For example, 2-10 fold increases 97 in the viscosity of liquid propane and butane are induced at TBTF concentrations of $0.15-0.30$ $98 \mathrm{wt} \%$ at $25^{\circ} \mathrm{C}$ and $8.3 \mathrm{MPa}(\sim 1200 \mathrm{psi})$, as determined with a high pressure, close-clearance, 99 falling cylinder viscometer [6]. Enick and co-workers later confirmed that liquid propane and 100 butane could be thickened with TBTF [11]. Heller's group also reported that TBTF was only 101 sparingly soluble in ethane [6] and induced no viscosity change in their sapphire crystal 102 viscometer that was rated to $20.7 \mathrm{MPa}(3000 \mathrm{psi})$ [12].

103 Other trialkyltin fluorides have also been considered as thickeners for light alkanes. Tripropyltin 104 fluoride is insoluble in hydrocarbon solvents, probably because the C3 arms are too short to 105 promote dissolution in the solvent [13]. Trialkyltin fluorides with longer n-alkyl arms have 106 proven much easier to dissolve, however. Dandge and co-workers found that triamyl-, trihexyl-, 107 trioctyl- and tridecyl-armed tin fluorides were soluble (> $0.4 \mathrm{wt} \%$ ) in normal alkanes higher than 108 propane as well as in solvents such as cyclopentane and cyclohexane in which tributyltin fluoride 109 was insoluble. However, in a comparison of viscosity change induced in solvents like n-hexane 110 (at $0.1 \mathrm{MPa}$ and $25^{\circ} \mathrm{C}$ ) and n-butane (at $8.3 \mathrm{MPa}$ and $25^{\circ} \mathrm{C}$ ), tributyltin fluoride clearly 
111 outperformed the others at equivalent molar concentrations in the alkane [6]. Apparently, the C4

112 arms are long enough to enable the compound to dissolve in the light alkane, yet so short that the

113 chain cannot readily bend toward the associating tin and fluoride atoms and disrupt the formation

114 of the linear associating polymer. The longer alkyl arms (C5 - C12) also facilitate dissolution in

115 the light alkanes, but these arms are apparently long and flexible enough to slightly interfere with

116 the associations between the tin and fluorine. For example, at a concentration of $12 \mathrm{mmol}^{-1}$ and

117 ambient condition of 1 atm $\& 25^{\circ} \mathrm{C}$, TBTF increased the viscosity of hexane by a factor of 240 ,

118 while triamyl-, trihexyl-, trioctyl- and tridecyl-armed tin fluorides increased the viscosity by

119 factors of only 100, 150, 120 and 80, respectively.

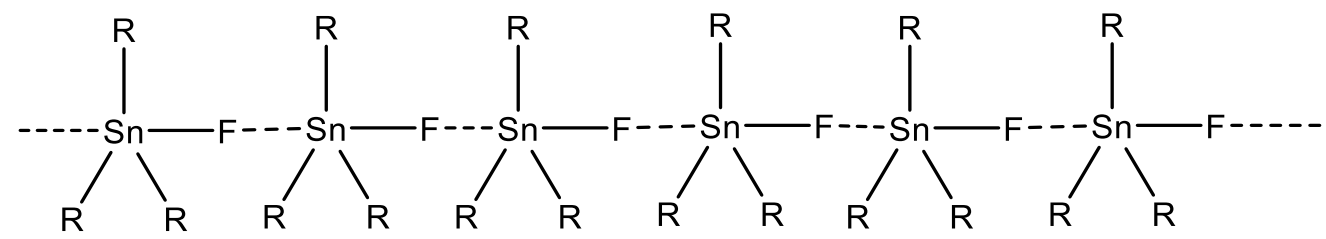

121 Fig. 1. Association in trialkyltin fluoride

\section{$122 \quad 1.2$ Hydroxyaluminum di-2-ethyl hexanoate (HAD2EH)}

123 A mixture of aluminum salts of naphthenic and palmitic acids, (often called "Napalm"), was 124 created during World War II to gel gasoline and hence weaponize this flammable liquid [14-16].

125 Typically, the mixture of the powdered aluminum disoap and the organic liquid is heated to a 126 temperature high enough to disrupt the intermolecular associations between organo-aluminum 127 molecules (promoting dissolution), and then cooled to allow the disoap molecules to self128 assemble into a viscosity-enhancing supramolecular structure, Fig. 2. Hydroxyaluminum di-2129 ethylhexanoate (HAD2EH), a powder with a melting point of $276^{\circ} \mathrm{C}$, is particularly effective in 130 thickening hydrocarbons. HAD2EH was also reported to be effective thickener for compressed 131 liquid propane and butane. At $20^{\circ} \mathrm{C}$ and HAD2EH concentrations of $0.2-1.0 \mathrm{wt} \%, 10-100$ fold 
132 viscosity increases were detected with a high pressure close-clearance falling cylinder

133 viscometer after many hours of mixing [7]. However, these HAD2EH-propane and HAD2EH-

134 butane solutions were not transparent - instead they were translucent and hazy, indicative that at

135 least a portion of the HAD2EH forms a network of insoluble interlocking fibers in the high

136 pressure liquid propane. Thickened solution composed of liquid propane or butane trapped

137 within a network of interlocking fibers would have great difficulty flowing through sandstone or

138 carbonate rock with pore throat diameters of $\sim 1$ micron. These fibers would be filtered out of

139 the solution by the surface of the rock into which the mixture was injected.

140
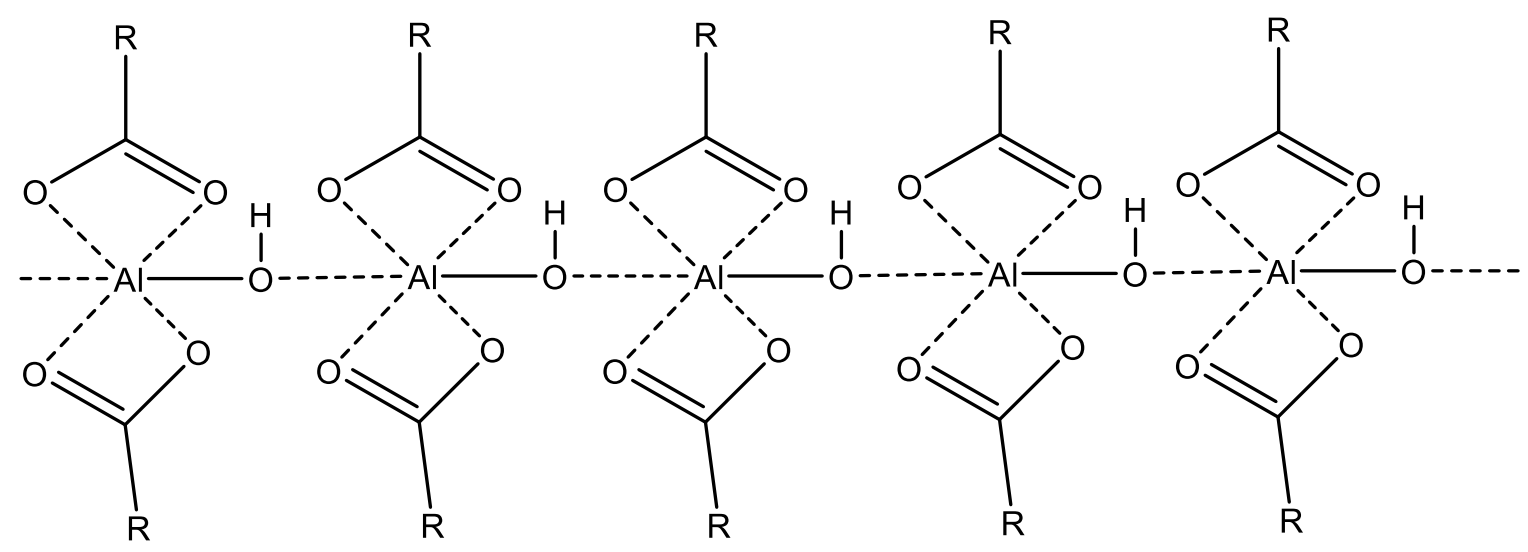

Fig. 2. Possible association of HAD2EH molecules [17]

\section{$142 \quad 1.3$ Crosslinked Phosphate Esters (CPE)}

143 Companies such as Halliburton, Ethox Chemicals, and Clearwater Inc. have patented techniques

144 for "gelling" light alkanes with phosphorous-based esters (Fig. 3), that are crosslinked with 145 polyvalent metal ions [8, 9, 18-21]. Phosphate (mono, di or the mixture of mono \& di) esters 146 with alkyl tails are used commonly. The main application of these gels, which are typically 147 formed with several weight percent of phosphate esters and crosslinking agents, is for dry 
148 hydraulic fracturing. In this work, the use of these compounds to thicken NGL at lower concentrations will be examined for possible EOR application.

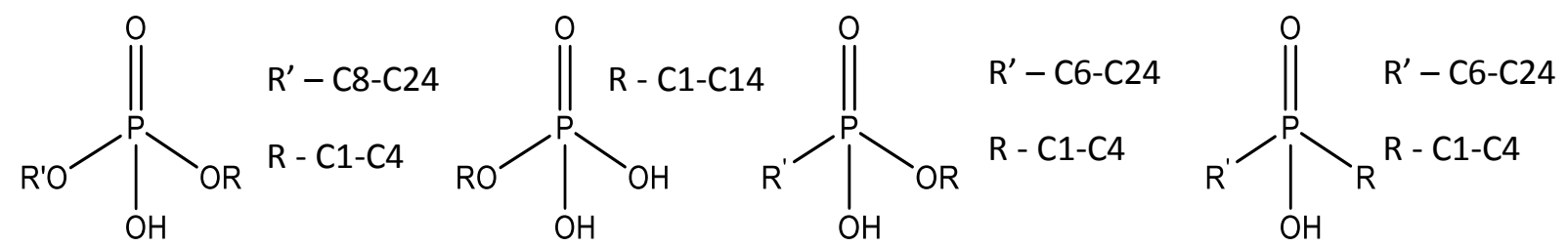

Fig. 3. Phosphate di-ester, Phosphate mono-ester, Phosphonic acid ester and Dialkyl phosphinic acid. Commonly 152 used R and R' group identities have been provided.

154 dissolved organometallic compound, are added to the liquid that is targeted for thickening. If the 155 polyvalent metal ion can be bound more tightly by the phosphate ester than the ligand that it was 156 originally formulated with in the crosslinker solution, then the phosphate esters will rapidly 157 chelate the metal ions without the need for a heating/cooling cycle and form a linear, 158 supramolecular, micellar structure (Fig. 4). If this extended associative structure remains soluble 159 in the liquid, it can quickly and dramatically enhance viscosity. The ease of pumping the 160 phosphate ester and the crosslinking solution, their fast dissolution in solvents, and the rapid 161 kinetics of viscosity enhancement are particularly attractive attributes for the possible use of 162 these phosphate ester systems for thickening NGL during field-scale EOR projects.

163 Oil-soluble phosphate mono/di-esters, alkyl phosphonic acid ester or dialkyl phosphinic acids 164 can be crosslinked with polyvalent metal ions such as $\mathrm{Fe}^{3+}, \mathrm{Al}^{3+}, \mathrm{Mg}^{2+}, \mathrm{Ti}^{4+}$ and $\mathrm{Zn}^{2+}$ to induce 165 significant viscosity changes (2-100 fold) in hydrocarbon liquids such as kerosene and diesel oil 


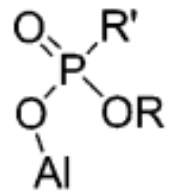

a

Pendant monodentate<smiles></smiles>

b

Chelating bidentate

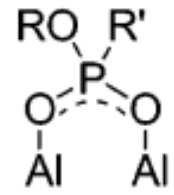

C

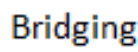

bidentate

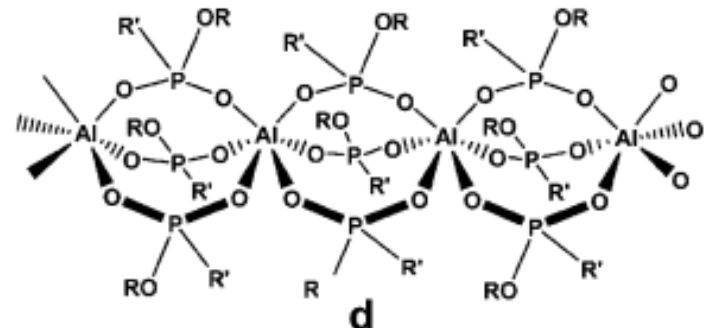

Micellar

structure

Fig. 4. Mechanism of chelating complex (phosphate ester with metal ion cross linker) [25-28]

Hydrocarbon fluids have been used for fracturing purposes since the 1970's [29, 30]. More recently there have been reports of gelled LPG used in fracturing applications [31, 32]. There

172 have been numerous reports of "gelled" LPG found in the literature [29-33]. However, due to an apparent desire to protect proprietary compositions and techniques, solubility and viscosity data

174 for gelled LPG is relatively scarce $[32,34]$.

Although TBTF, HAD2EH and CPE have been reported to be potential thickeners for one or more components of NGL, a thorough comparison of the performance of these components in

177 ethane, propane and butane has not been presented. For example, TBTF is known to thicken

178 propane and butane while exhibiting minimal solubility in ethane, but the solubility of TBTF in

179 ethane at pressures above 20.68 MPa has not been evaluated. HAD2EH has only been assessed in propane at room temperature, but its ability to thicken ethane, propane and butane over any

181 temperature range has not been reported. CPE is known to gel organic liquids at ambient temperature and pressure, but claims that CPEs can gel NGL have not been substantiated by phase behavior and viscosity studies for mixtures of CPEs with ethane, propane or butane. 
184 Therefore, the objective of this study is to assess the abilities of TBTF, HAD2EH and CPE to 185 dissolve in and thicken the three main components of NGL (ethane, propane and butane) in the $18625-100^{\circ} \mathrm{C}$ temperature range at pressures to $62.05 \mathrm{MPa}$.

\section{2. Experimental}

$188 \quad 2.1 \quad$ Materials

189 n-pentane (Reagent grade, 98\% purity) was purchased from Sigma Aldrich and used as received 190 for ambient pressure screening tests. Ethane, propane and n-butane were obtained from 191 Matheson with a purity level of $99.99 \%$ and used without further purification.

192 TBTF (93\% purity) and HAD2EH (96\% purity) were procured from TCI America and BOC 193 Science, respectively, and were used as received.

194 Six Lubrizol Oilfield Solutions (LZOS) phosphate ester products (HGA 70, HGA 70-C6, HGA 195 37, HGA 37D, HGA 715LP and HGA 702) and three LZOS crosslinking solutions (HGA 65, 196 HGA 48, and HGA 44) were provided by LZOS and used as received. Specific compositions of 197 these proprietary products were not provided, although the MSDS of HGA 48 indicates that $198 \mathrm{AlCl}_{3}$ is present. Each crosslinking solution contains a compound with a polyvalent ion. For 199 example, HGA-65 is an organometallic complex that contains a metal ion with a +3 charge that 200 combines with a phosphate ester-based gelling agent, such as HGA-70, to form stable 201 hydrocarbon gels rapidly. For all 18 combinations of phosphate ester and crosslinker, the LZOS 202 products are designed to be used in equal mass concentrations in order to have the appropriate 203 stoichiometric amounts of phosphate ester and polyvalent crosslinker. 
$204 \quad 2.2 \quad$ Ambient pressure viscometry

205 A rotating-dish-and-cup viscometer (Brookfield DV-II+ Programmable Viscometer, M/97-164-

206 D1000) instrument was used for measuring the viscosity of thickened pentane at atmospheric 207 pressure [35].

\subsection{Phase behavior measurement}

209 A windowed, variable-volume view cell was used to conduct non-sampling cloud point pressure 210 measurements of mixtures of each thickener in ethane, propane or butane. The details of this 211 experimental procedure for determining thickener solubility have been presented in detail 212 elsewhere [36-38]. In general, a transparent single phase for a mixture of known overall 213 composition was first attained by mixing the thickener (e.g. TBTF or HAD2EH) and the light 214 alkane at pressures as high as $69 \mathrm{MPa}$ at the temperature of interest. In some cases the mixture 215 was also heated to temperatures up to $100^{\circ} \mathrm{C}$ in order to disrupt the intermolecular associations 216 between thickener molecules, thereby facilitating dissolution; the mixture was then cooled 217 isobarically to the temperature of interest. In the case of the two-component CPE thickener 218 (phosphate ester + crosslinker), the phosphate ester HGA 70-C6 was placed in a small open glass 219 dish at the bottom of the sample volume, while the crosslinker solution HGA 65 was poured 220 around the glass dish. The alkane was then slowly added to the sample volume. This prevented 221 the phosphate ester and the crosslinker from reacting prior to the HGA 70-C6 being dissolved in 222 the high pressure alkane. The transparent single fluid phase was then very slowly expanded at 223 constant temperature until a cloud point (i.e. the appearance of small particles of the thickener)

224 was observed. The cloud point measurement was repeated three times and the average cloud 225 point reported. Typically the error in measurement of cloud point and temperature is $\pm 0.7 \mathrm{MPa}$ 226 and $\pm 0.1^{\circ} \mathrm{C}$, respectively. 


\section{$227 \quad 2.4 \quad$ High pressure viscometry}

228 A close-clearance, high pressure, windowed, invertible, falling ball viscometer was employed for 229 obtaining the relative viscosity [35]. In a typical experiment, the transparent single phase 230 solution at a pressure above the cloud point of the solution is established in the Pyrex tube 231 (3.1750 $\mathrm{cm}$ inside diameter). A Pyrex ball $\left(2.23 \mathrm{~g} / \mathrm{cm}^{3}, 3.1587 \mathrm{~cm}\right.$ diameter) is also present at the 232 bottom of the sample volume. The entire cell is then inverted rapidly and the terminal velocity of 233 ball is measured at the mid-point of its fall by measuring the time required for the ball to fall 2 $234 \mathrm{~cm}$. The terminal velocity is also measured in the neat solvent (ethane, propane or butane). 235 Terminal velocity measurements are repeated 10 times and average terminal velocity is recorded.

236 The relative viscosity is the ratio of the viscosity of the fluid with a dissolved thickener to the

237 viscosity of the pure fluid, $\frac{\mu_{\text {sol }}}{\mu_{\mathrm{o}}}$. If one assumes that the dilute concentration of polymer does not 238 significantly affect fluid density, then the relative viscosity as measured with a close-clearance 239 falling object viscometer can be expressed as follows [35, 39-41].

$$
\text { Relative Viscosity }=\frac{\mu_{\text {sol }}}{\mu_{\mathrm{o}}}=\frac{V_{t}}{V_{\text {sol }}}
$$

240 Where, $\mu_{\text {sol }}$ is the viscosity of solution containing a specified amount of thickener, $\mu_{\mathrm{o}}$ is the 241 viscosity of the pure fluid, $V_{t}$ is the terminal velocity of the ball in the pure fluid and $\mathrm{V}_{\text {sol }}$ is the 242 terminal velocity of the ball in solution with thickener compound. Our group has used this 243 procedure previously to determine the effectiveness of a polyfluoroacrylate polymer to thicken $244 \mathrm{CO}_{2}[7,39,40]$. We have recently shown that for our Pyrex ball of diameter of $3.1587 \mathrm{~cm}$, 245 density of $2.23 \mathrm{gr} / \mathrm{cm}^{3}$ and cylinder inner diameter of $3.175 \mathrm{~cm}$, the average shear rate over the 246 surface of the falling ball is [35] 


$$
\gamma_{a v g}\left(s^{-1}\right) \approx 7000 V_{t}\left(\frac{c m}{s}\right)
$$

\section{3. Results and discussion}

\section{$248 \quad 3.1 \quad$ Thickened pentane}

249 In order to ascertain the approximate concentration range over which significant increases in 250 viscosity could be expected in our high pressure testing of NGL, each of the thickening agents 251 was "screened" by dissolving it in n-pentane. The viscosity of the resultant solutions was 252 determined over the shear rate range of $15-450 \mathrm{~s}^{-1}$ at $23^{\circ} \mathrm{C}$ and $1 \mathrm{~atm}$; the results at a shear rate of $253325 \mathrm{~s}^{-1}$ are presented in Fig. 5. Higher mass fractions of each thickener dissolved in the pentane, 254 but the viscosity of the resultant solutions exceeded the limits of the Brookfield viscometer. Note 255 that the viscosity values for the HAD2EH solution correspond to data obtained at $30^{\circ} \mathrm{C}$ (rather 256 than $23^{\circ} \mathrm{C}$ ) because dissolution of HAD2EH requires heating to $\sim 100^{\circ} \mathrm{C}$ followed by cooling to 257 temperatures no lower than $30^{\circ} \mathrm{C}$; at lower temperatures the $\mathrm{HAD} 2 \mathrm{EH}$ precipitates from solution.

258 In case of the CPE, the use of the HGA 70-C6 phosphate ester and the HGA 65 crosslinker was 259 found to be the most effective pairing of the 18 possible combinations of six phosphate esters 260 and three crosslinkers.

261 In order to put the size of the long, linear transient polymers or micelles formed by these small 262 associating compounds in perspective, the viscosity increase associated with a poly- $\alpha$-olefin with 263 a molecular weight greater than $20,000,000$ is also shown in Fig. 5 [35, 41]. At these relatively 264 low temperatures, the ranking of the thickeners (starting with the best at a specified wt\% 265 concentration) is CPE, DRA, HAD2EH, and TBTF. Further, Fig. 5 indicates that, in general, 0.1 $266-0.4 \mathrm{wt} \%$ of these thickeners is required for order-of-magnitude changes in solution viscosity. 


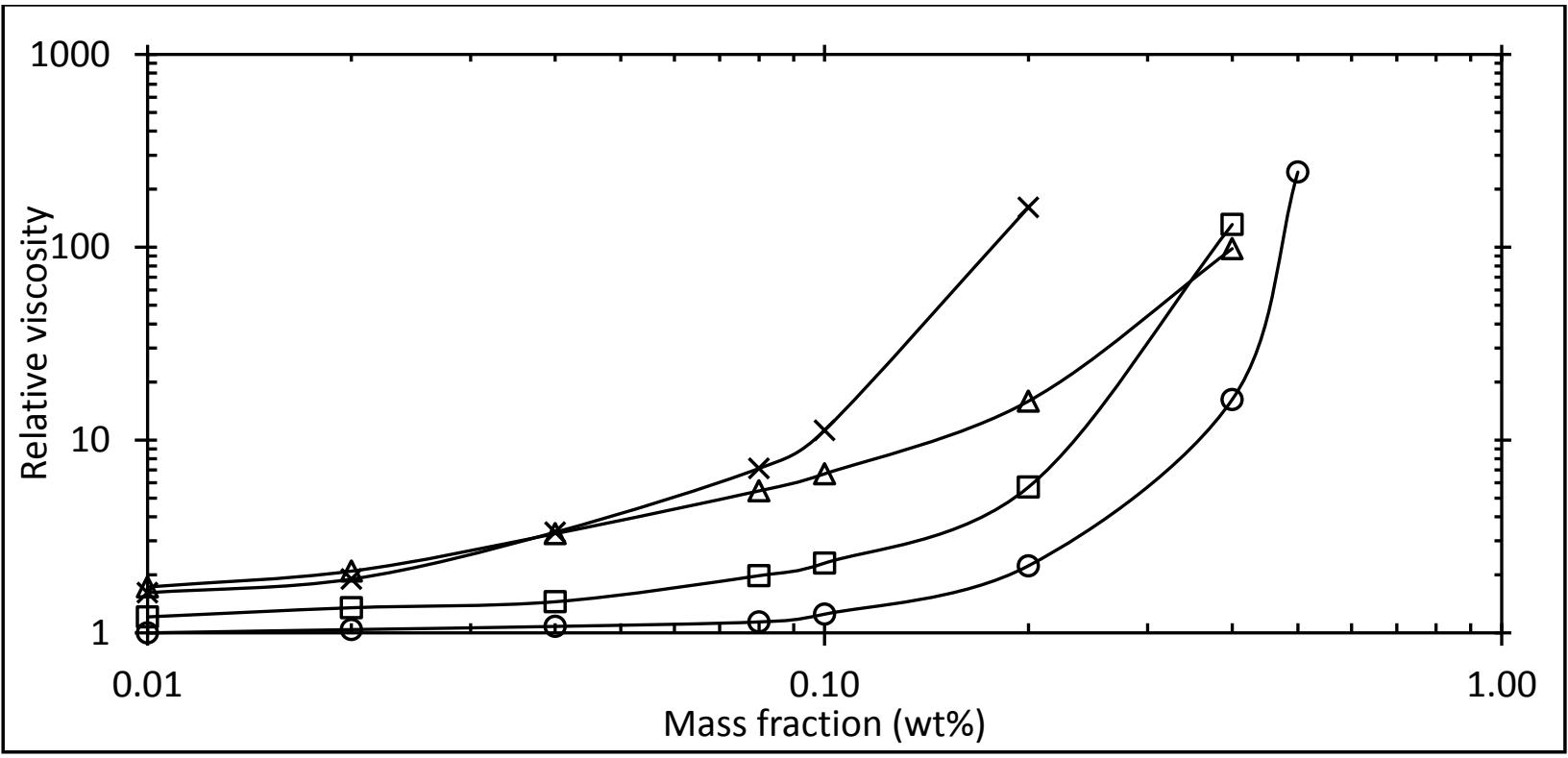

Fig. 5. Relative viscosity (viscosity of pentane solution/viscosity of pentane) at $325 \mathrm{~s}^{-1}$. x HGA 70-C6 and HGA 65 at $23^{\circ} \mathrm{C} ; \Delta$ poly $(\alpha$-olefin $)$ at $23^{\circ} \mathrm{C}$; $\quad \mathrm{HAD} 2 \mathrm{EH}$ at $30^{\circ} \mathrm{C}$; $\circ$ TBTF at $23^{\circ} \mathrm{C}$.

3.2 High pressure ethane, propane and n-butane results

\subsubsection{TBTF}

272 TBTF dissolves quickly up to $1 \mathrm{wt} \%$ in ethane, propane and n-butane at pressures above the

273 cloud point values listed in Table 1. The cloud point pressures required to dissolve TBTF in

274 propane and n-butane are only slightly above the vapor pressure of the respective fluids.

275 Dissolution in ethane, however, requires pressures significantly greater than ethane's vapor 276 pressure. This is not surprising because ethane is generally a weaker solvent for organometallic 277 compounds than propane and butane. This is reflected by the very low value of the solubility 278 parameter for liquid ethane, $11.7 \mathrm{MPa}^{0.5}$, relative to that of liquid propane, $13.4 \mathrm{MPa}^{0.5}$, and 279 liquid $n$-butane, $14.1 \mathrm{MPa}^{0.5}$ [42]. Note that all of the cloud point pressures listed for ethane in 280 Table 1 exceed $20.68 \mathrm{MPa}$, which was the pressure limit of the viscometer used by Heller and 281 co-workers when they reported that TBTF was sparingly ethane-soluble [6]. 
Table 1- Cloud point pressure of TBTF in NGL

\begin{tabular}{|c|c|c|c|c|c|c|}
\hline \multirow{2}{*}{ Solvent } & \multirow{2}{*}{$\begin{array}{c}\text { TBTF concentrations } \\
(\mathrm{wt} \%)\end{array}$} & \multicolumn{5}{|c|}{ Cloud point (MPa) } \\
\hline & & $25^{\circ} \mathrm{C}$ & $40^{\circ} \mathrm{C}$ & $60^{\circ} \mathrm{C}$ & $80^{\circ} \mathrm{C}$ & $100^{\circ} \mathrm{C}$ \\
\hline \multirow{4}{*}{ Ethane } & 0.20 & 33.34 & 35.30 & 39.96 & 42.30 & 44.61 \\
\hline & 0.50 & 38.16 & 40.78 & 44.47 & 46.16 & 47.68 \\
\hline & 0.75 & 38.92 & 41.33 & 44.95 & 47.02 & 48.44 \\
\hline & 1.00 & 40.44 & 42.85 & 47.23 & 48.33 & 50.68 \\
\hline \multirow{2}{*}{ Propane } & 0.50 & 1.05 & 1.59 & 2.45 & & \\
\hline & 1.00 & 1.07 & 1.64 & 2.55 & & \\
\hline \multirow{2}{*}{ n-Butane } & 0.50 & 0.31 & 0.42 & 0.77 & & \\
\hline & 1.00 & 0.36 & 0.43 & 0.79 & & \\
\hline
\end{tabular}

284 The relative viscosity of the high pressure solutions of TBTF in ethane, propane and n-butane are 285 provided in the Figs. 6-9. Fig. 6 presents the thickening results for ethane at $25^{\circ} \mathrm{C}$ as a function 286 of TBTF concentration and pressure. The viscosity of the solution increases significantly with 287 TBTF concentration, with only slight increases in viscosity versus pressure. Similar trends were 288 observed at temperatures as high as $100^{\circ} \mathrm{C}$. The relative viscosity values for solutions of TBTF 289 in ethane at a single pressure of $62.05 \mathrm{MPa}$ are presented in Fig. 7 as a function of TBTF 290 concentration (x-axis) and temperature for several isotherms. Clearly, once TBTF concentration 291 reaches approximately $0.5 \%$, viscosity begins to increase rapidly with further concentration 292 increases. Figs. 6 and 7 constitute the first known report that TBTF can dissolve ethane in and 293 thicken ethane. 
294 As previously noted by Heller and coworkers [6] and Enick and co-workers [11], very large 295 increases in propane and butane viscosity are achieved with TBTF (e.g. $70-100$ fold at $25^{\circ} \mathrm{C}$ ). 296 Because the TBTF-induced relative viscosity changes for propane and butane are also only 297 slightly sensitive to changes in pressure, only the relative viscosity values at a pressure of 6.89 $298 \mathrm{MPa}$ are presented as a function of temperature and TBTF concentration in Fig. 8 for propane 299 and Fig. 9 for butane. As in the case of ethane, viscosity begins to increase rapidly with 300 concentration above $0.5 \%$.

301 There is only a very slight increase in relative viscosity with increasing pressure at any 302 temperature and TBTF concentration. This effect is in contrast to the significant increases in 303 relative viscosity with increasing pressure that are observed when ultrahigh molecular weight 304 polymers are used to thicken light alkanes [35], where increased alkane density and solvent 305 strength promote the swelling of polymer coils. TBTF, on the other hand, is a small molecule 306 that self-assembles into a linear supramolecular structure. As long as the TBTF is fully dissolved, 307 further increases in pressure-induced solvent strength apparently do not have a significant effect 308 on solution viscosity.

309 Increasing temperature above $40^{\circ} \mathrm{C}$ significantly diminishes the intermolecular associations 310 between the tin and fluorine of adjacent TBTF molecules, resulting in notable decreases in 311 relative viscosity for all of the light alkanes. For example, at $25^{\circ} \mathrm{C}, 1 \% \mathrm{TBTF}$ in ethane and 62.05 312 MPa produces a relative viscosity of 90 . At $40^{\circ} \mathrm{C}$, the relative viscosity under similar conditions 313 is 75 . At $60^{\circ} \mathrm{C}, 80^{\circ} \mathrm{C}$ and $100^{\circ} \mathrm{C}$, the relative viscosity drops to 20,6 and 2 , respectively. 


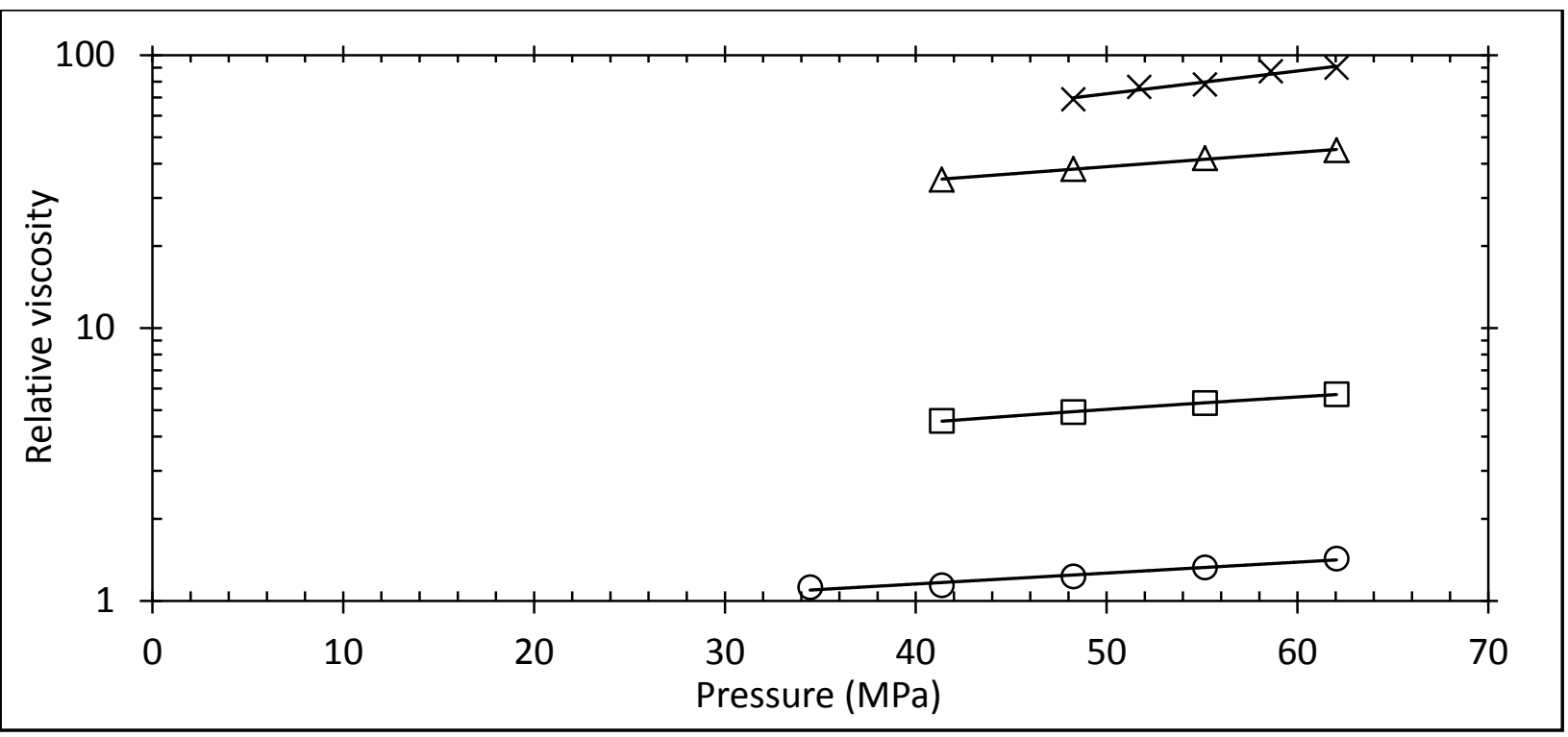

Fig. 6. Viscosity change in ethane by $\mathrm{TBTF}$ at $25^{\circ} \mathrm{C}$ and average shear rate (Equation 2) of 100-7100 $\mathrm{s}^{-1}$ (Logarithmic Y-axis). $x$ TBTF at $1 \mathrm{wt} \%$; $\Delta$ TBTF at $0.75 \mathrm{wt} \%$; $\square$ TBTF $0.5 \mathrm{wt} \%$; $\circ$ TBTF $0.2 \mathrm{wt} \%$.

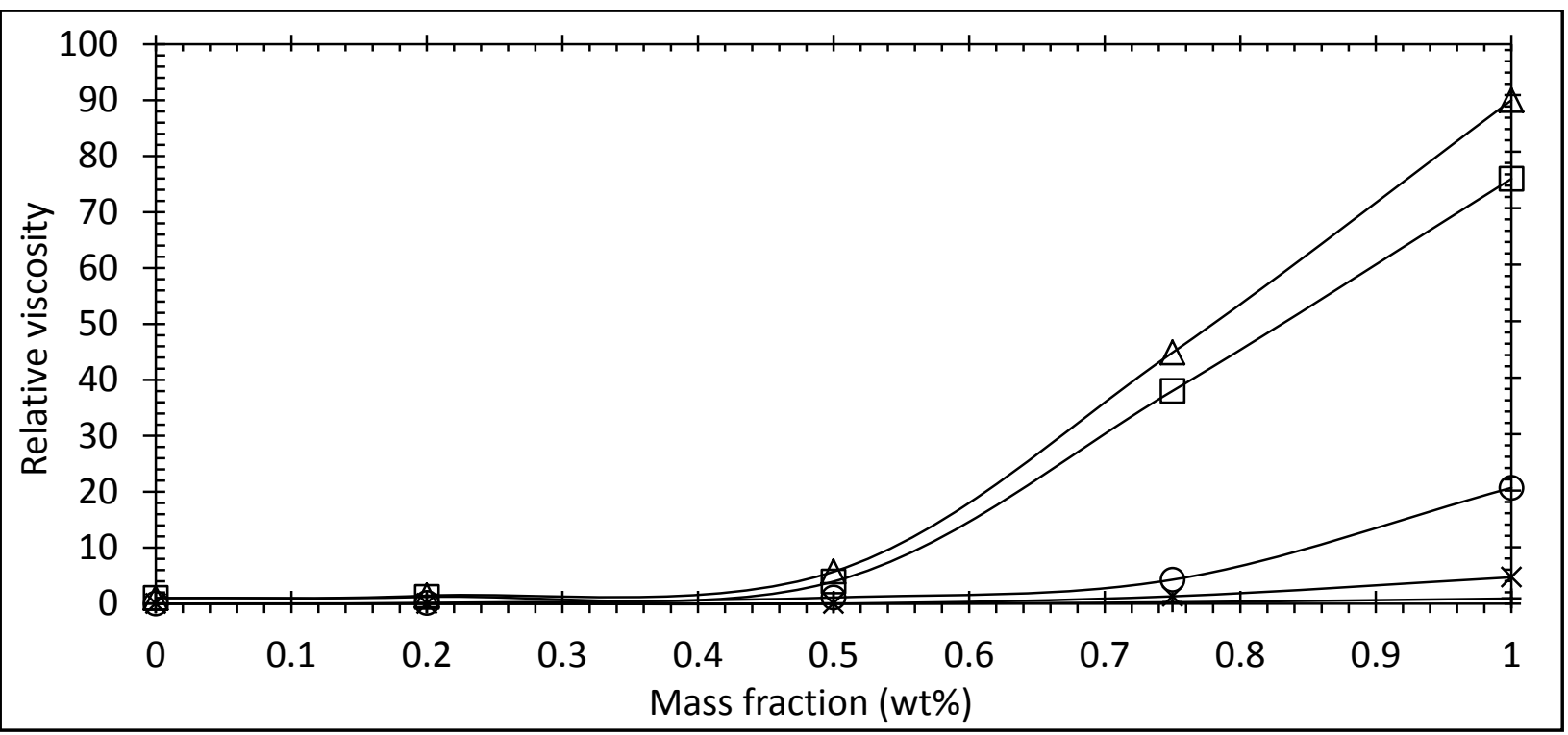

Fig. 7. Increase in ethane viscosity caused by $\mathrm{TBTF}$ at $\mathrm{P}=62.05 \mathrm{MPa}$ and average shear rate (Equation 2 ) of 100$7100 \mathrm{~s}^{-1} . \Delta \mathrm{TBTF}$ at $25^{\circ} \mathrm{C}$; $\square$ TBTF at $40^{\circ} \mathrm{C} ;$ o TBTF at $60^{\circ} \mathrm{C} ; \mathrm{x}$ TBTF at $80^{\circ} \mathrm{C} ;+\mathrm{TBTF}$ at $100^{\circ} \mathrm{C}$. 


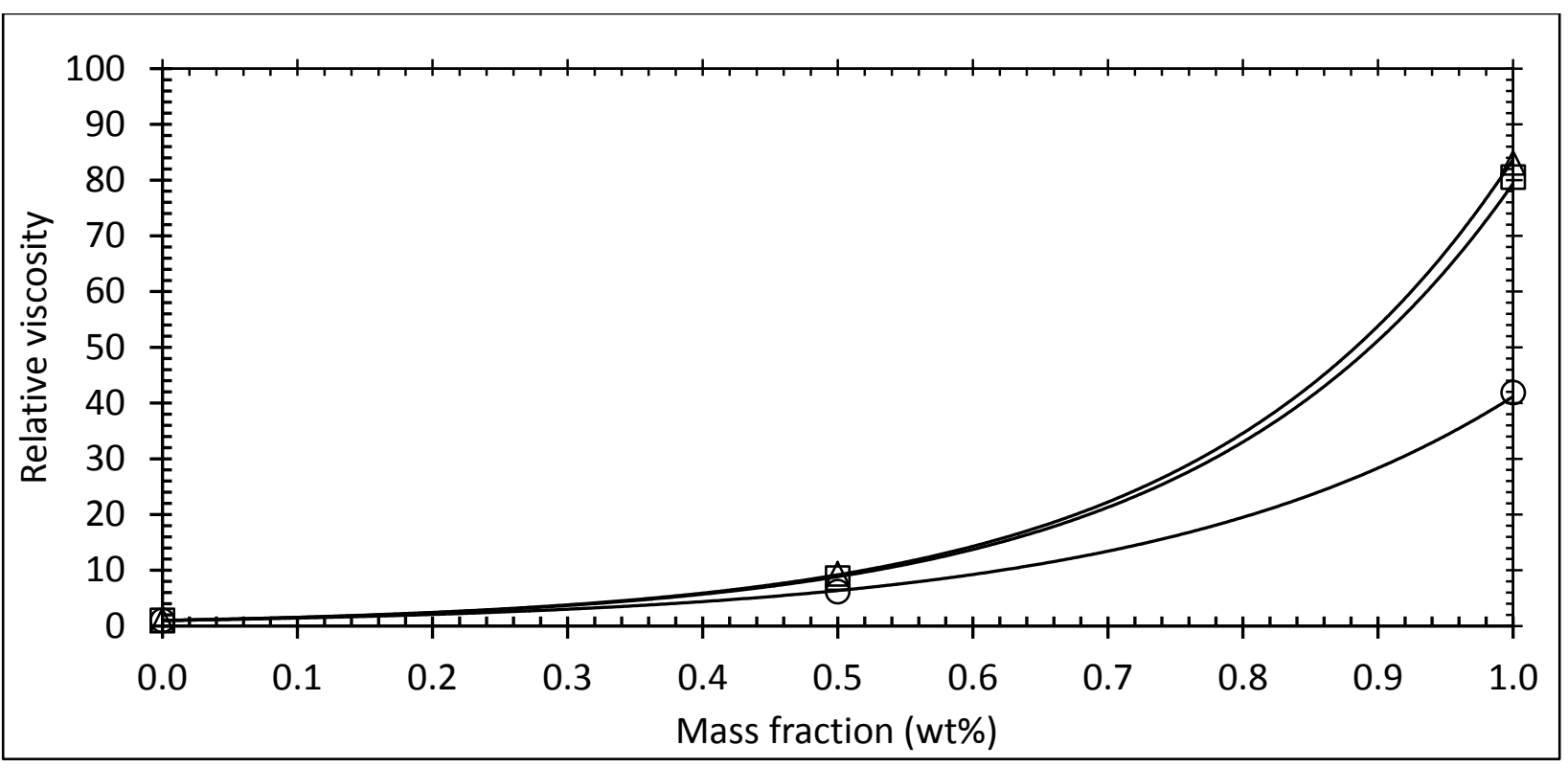

321 Fig. 8. Increase in propane viscosity caused by TBTF at $\mathrm{P}=6.89 \mathrm{MPa}$ and average shear rate (Equation 2 ) of 120 -

$3227100 \mathrm{~s}^{-1} . \Delta$ TBTF at $25^{\circ} \mathrm{C}$; $\square$ TBTF at $40^{\circ} \mathrm{C}$; $\circ$ TBTF at $60^{\circ} \mathrm{C}$.

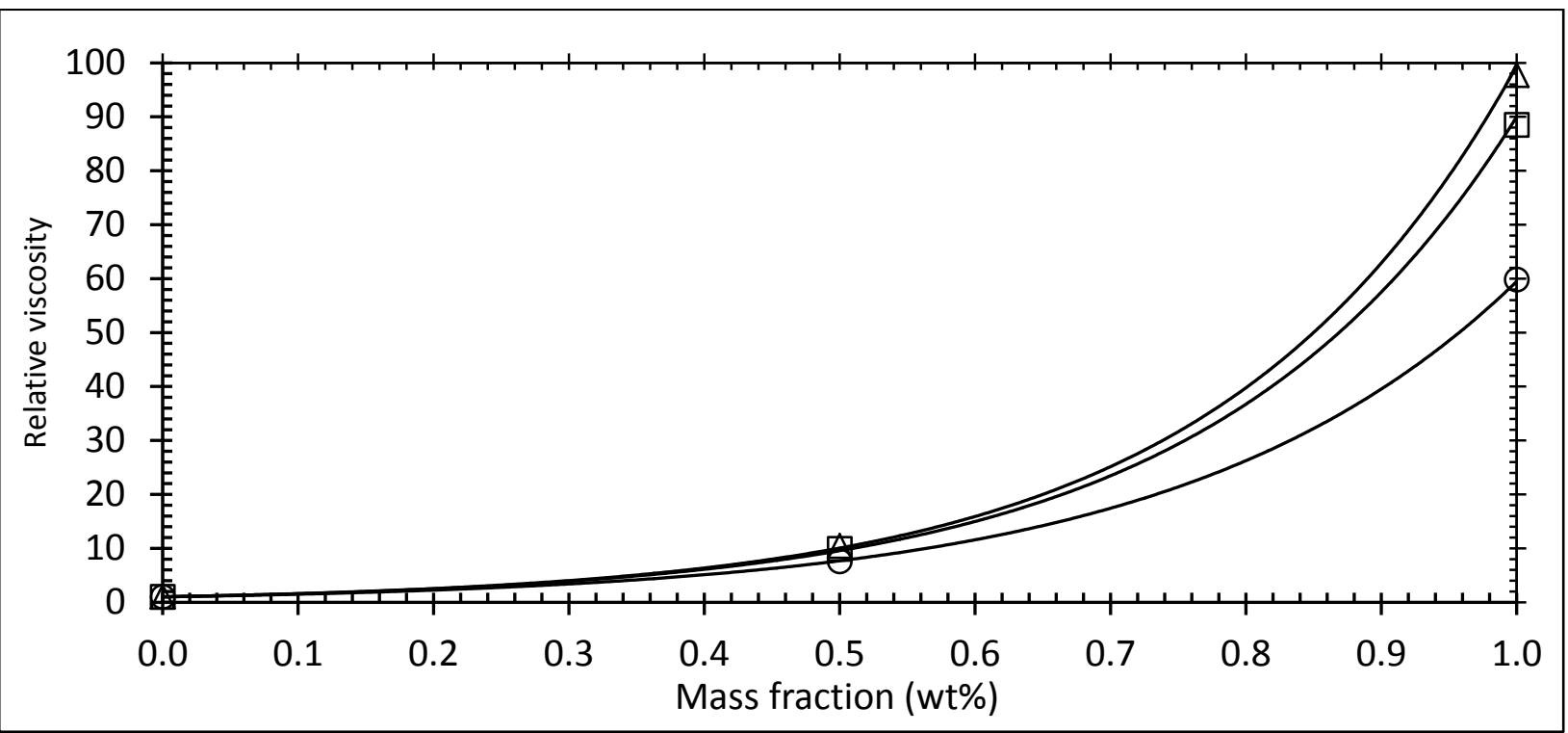

324 Fig. 9. Increase in butane viscosity caused by $\mathrm{TBTF}$ at $\mathrm{P}=6.89 \mathrm{MPa}$ and average shear rate (Equation 2$)$ of $90-7100$ $325 \mathrm{~s}^{-1} . \Delta$ TBTF at $25^{\circ} \mathrm{C} ; \square \quad \mathrm{TBTF}$ at $40^{\circ} \mathrm{C} ;$ o $\mathrm{TBTF}$ at $60^{\circ} \mathrm{C}$. 


\subsubsection{Hydroxyaluminum di-2-ethyl hexanoate (HAD2EH) results}

$327 \mathrm{HAD} 2 \mathrm{EH}$ is ethane-insoluble at pressures to $69 \mathrm{MPa}$ and temperatures to $100^{\circ} \mathrm{C}$. The solubility 328 of the $\mathrm{HAD} 2 \mathrm{EH}$ in propane and butane at $25^{\circ} \mathrm{C}, 40^{\circ} \mathrm{C}, 60^{\circ} \mathrm{C}, 80^{\circ} \mathrm{C}$ and $100^{\circ} \mathrm{C}$ is provided in 329 Table 2. Unlike TBTF, the dissolution of HAD2EH in light alkanes requires heating the high 330 pressure mixture to a temperature of $\sim 100^{\circ} \mathrm{C}$ during mixing, attaining a clear solution, and then 331 cooling the solution to the target temperature. HAD2EH remains in solution down to 332 temperatures of $40^{\circ} \mathrm{C}$, but precipitates at $25^{\circ} \mathrm{C}$ in both propane and butane. These solubility 333 results in propane differ somewhat from the earlier report of Enick [7], who reported that 334 HAD2EH obtained from Eastman Kodak could not dissolve in propane, but HAD2EH received 335 from Pfaltz and Bauer did dissolve in propane after a many hours of mixing at $20^{\circ} \mathrm{C}$. It is 336 possible that the Pfaltz and Bauer product may have contained an impurity such as ethylhexanoic 337 acid that enhanced the solubility of HAD2EH in propane.

Table 2 - Cloud point data for solutions of HADEH in propane and butane

\begin{tabular}{|c|c|c|c|c|c|c|}
\hline & \multirow{2}{*}{$\begin{array}{c}\text { HADEH concentrations } \\
(\mathrm{wt} \%)\end{array}$} & \multicolumn{5}{|c|}{ Cloud point (MPa) } \\
\hline & & $25^{\circ} \mathrm{C}$ & $40^{\circ} \mathrm{C}$ & $60^{\circ} \mathrm{C}$ & $80^{\circ} \mathrm{C}$ & $100^{\circ} \mathrm{C}$ \\
\hline \multirow{2}{*}{ Ethane } & 0.50 & Insoluble & Insoluble & Insoluble & Insoluble & Insoluble \\
\hline & 1.00 & Insoluble & Insoluble & Insoluble & Insoluble & Insoluble \\
\hline \multirow{2}{*}{ Propane } & 0.50 & Insoluble & 1.59 & 2.45 & 3.53 & 5.38 \\
\hline & 1.00 & Insoluble & 1.64 & 2.55 & 3.62 & 5.62 \\
\hline \multirow{2}{*}{ n-Butane } & 0.50 & Insoluble & 0.42 & 0.77 & 1.12 & 1.75 \\
\hline & 1.00 & Insoluble & 0.43 & 0.79 & 1.14 & 1.76 \\
\hline
\end{tabular}


In all cases the $\mathrm{HAD} 2 \mathrm{EH}$-alkane mixture was heated to $100^{\circ} \mathrm{C}$ at high pressure while being mixed, followed by cooling to the temperature listed in Table 2 . The relative viscosity of HAD2EH-thickened solutions of propane and butane is shown in Fig. 10. Increasing pressure to values up to $62.05 \mathrm{MPa}$ has little effect on relative viscosity [41], therefore only the relative viscosity results at 6.89 $\mathrm{MPa}$ are presented. Surprisingly, only modest decreases in viscosity were observed with increasing target temperature. Further, HAD2EH is a much more effective thickener of butane than propane. For example, at a concentration of $1 \mathrm{wt} \% \mathrm{HAD} 2 \mathrm{EH}$ in butane 347 at $40^{\circ} \mathrm{C}$, the transparent solution is so viscous that the Pyrex ball does not fall, while the viscosity 348 of propane increases only by a factor of 14 . At $0.5 \mathrm{wt} \% \mathrm{HAD} 2 \mathrm{EH}$ and at $100^{\circ} \mathrm{C}$, butane is thickened by a factor of 14, while propane viscosity increases by a factor of 3 .

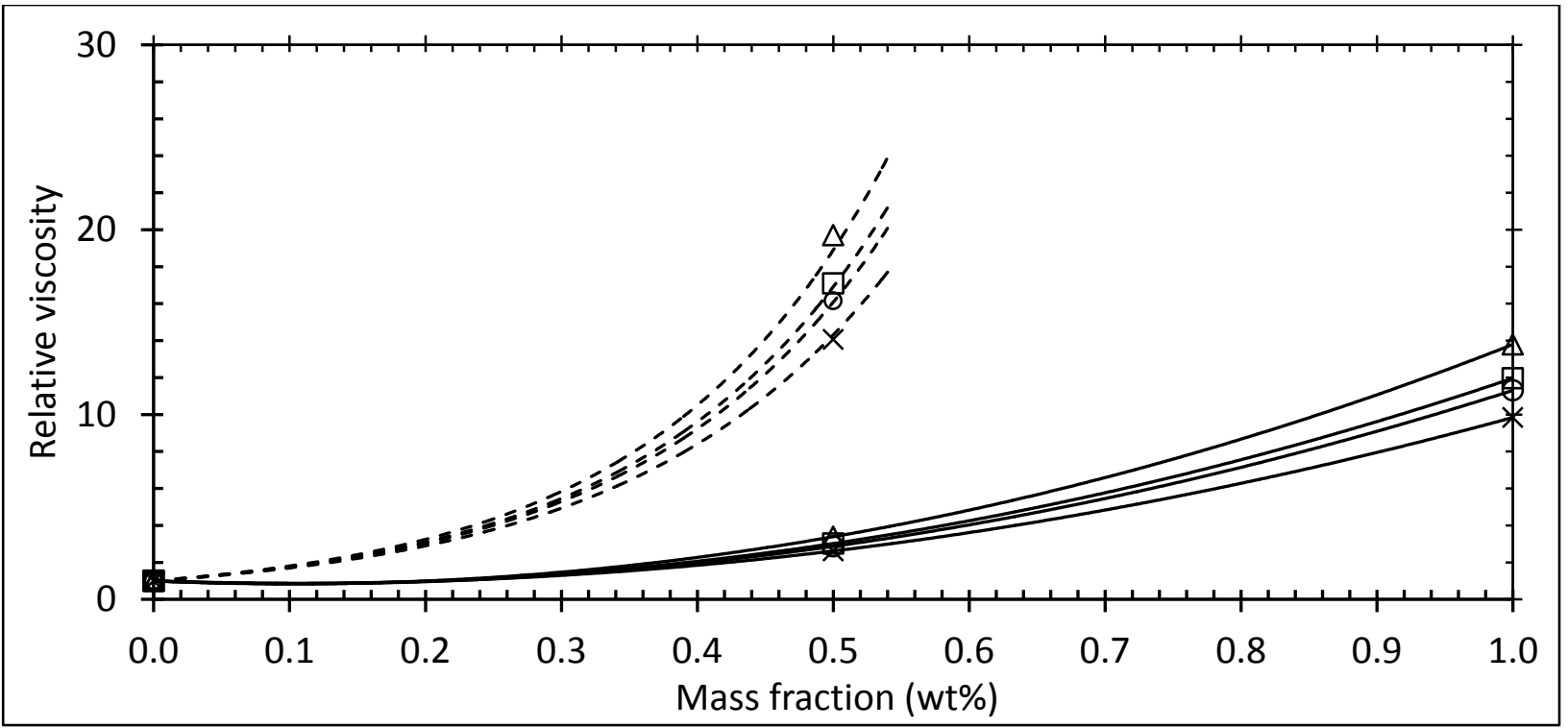

Fig. 10. Increase in propane (represented by smooth solid curves) and butane viscosity (represented by smooth

352 dashed curves) caused by HADEH at $\mathrm{P}=6.89 \mathrm{MPa}$ and average shear rate (Equation 2) of $350-7100 \mathrm{~s}^{-1} . \Delta$ $353 \mathrm{HADEH}$ at $40^{\circ} \mathrm{C}$; $\square \mathrm{HADEH}$ at $60^{\circ} \mathrm{C}$; $\bigcirc \mathrm{HADEH}$ at $80^{\circ} \mathrm{C}$; $\mathrm{x} \mathrm{HADEH}$ at $100^{\circ} \mathrm{C}$. (In butane, at concentration of $1.00 \mathrm{wt} \%$ for $40^{\circ} \mathrm{C}<\mathrm{T}<100{ }^{\circ} \mathrm{C}$, the solution was so viscous that the ball did not fall) 
3.2.3 Crosslinked Phosphate ester (CPE): Phosphate ester (HGA 70-C6) and cross linker (HGA 65)

357 This phosphate ester (HGA 70-C6) is soluble to at least $1 \mathrm{wt} \%$ in high pressure liquid ethane, 358 propane and butane at $25^{\circ} \mathrm{C}$ at pressures less than $1 \mathrm{MPa}$ above the alkane vapor pressure. 359 However, the HGA 65 cross linker solution is not completely soluble in pentane or in the high 360 pressure ethane, propane or butane. A small amount of a second liquid phase (possibly the 361 solvent used in the preparation of the HGA 65) appears when HGA 65 is combined with any of 362 these alkanes at pressures to $69 \mathrm{MPa}$. Therefore (unlike the TBTF and HAD2EH solutions), a 363 transparent single phase does not result when the phosphate ester and crosslinker are combined 364 in any of the NGL constituents. Rather, at very high pressures these mixtures appear as a slightly 365 hazy, translucent fluids that contain a very small amount of suspended, sub-millimeter droplets. 366 As this mixture is expanded, a pressure is reached where significant precipitation occurs that 367 renders the mixture completely opaque. The pressure at which this occurs is designated as the 368 "cloud point" of the translucent phase.

Table 3 - Cloud point* data for CPE in light alkanes; phosphate ester HGA-70 C6 and cross linker HGA65

\begin{tabular}{lcccc}
\hline \multirow{2}{*}{$\begin{array}{c}\text { Solvent } \\
\text { Combined concentrations }\end{array}$} & \multicolumn{4}{c}{ Cloud point* } \\
& $(\mathbf{w t} \%)$ & & $(\mathbf{M P a})$ & \\
& & $\mathbf{2 5}^{\mathbf{0}} \mathbf{C}$ & $\mathbf{4 0}^{\mathbf{0}} \mathbf{C}$ & $\mathbf{6 0}^{\mathbf{0}} \mathbf{C}$ \\
& 0.25 & 10.41 & 10.51 & 10.69 \\
Ethane & 0.50 & 11.10 & 11.38 & 11.78 \\
& 1.00 & 15.89 & 17.00 & 18.03 \\
& & & & \\
\hline & 0.25 & 1.07 & 1.52 & 2.29 \\
Propane & 0.50 & 1.07 & 1.52 & 2.26
\end{tabular}




\begin{tabular}{llll}
1.00 & 1.06 & 1.48 & 2.24 \\
\hline 0.5 & 0.28 & 0.42 & 0.74
\end{tabular}

n-Butane

$\begin{array}{llll}1.0 & 0.29 & 0.42 & 0.76\end{array}$

*Unlike the TBTF and HAD2EH systems that formed transparent single phases, these CPE cloud point values

371 correspond to the transition from a translucent phase with small suspended droplets to a completely opaque mixture

372 The relative viscosity of CPE-thickened ethane, propane and butane at pressures above the cloud

373 point pressure of the mixture was determined at 25,40 and $60^{\circ} \mathrm{C}$. In all cases, the small droplets

374 suspended in the thickened alkane have no difficulty flowing around the falling ball, therefore

375 falling ball viscometry was used to estimate viscosity. The ability of the (phosphate ester +

376 crosslinker) mixture to thicken the light alkanes increased slightly with increasing pressure and

377 decreased with increasing temperature [41], therefore the results for ethane, propane and butane

378 are presented in Figs. 11, 12 and 13, respectively, only for the pressure of 20.68 MPa.

379 A very modest viscosity enhancement occurs with the addition of the (phosphate ester + 380 crosslinker) mixture to ethane. For example, at a combined concentration of $1 \mathrm{wt} \%$ at $25^{\circ} \mathrm{C}$ and $38120.68 \mathrm{MPa}$, the viscosity increased by a factor of only 1.9. Greater increases were observed in 382 propane, and the largest viscosity increases occur when butane is thickened. For example, at a 383 combined concentration of $1 \mathrm{wt} \%$ at $25^{\circ} \mathrm{C}$ and $20.68 \mathrm{MPa}$, the viscosity of propane and butane 384 increased by a factor of 3.0 and 5.3, respectively. These increases are much less significant that 385 those attained with CPE in pentane. Further, the CPE-induced viscosity enhancement of the 386 NGL components is much less significant that those realized with either TBTF or HAD2EH. 


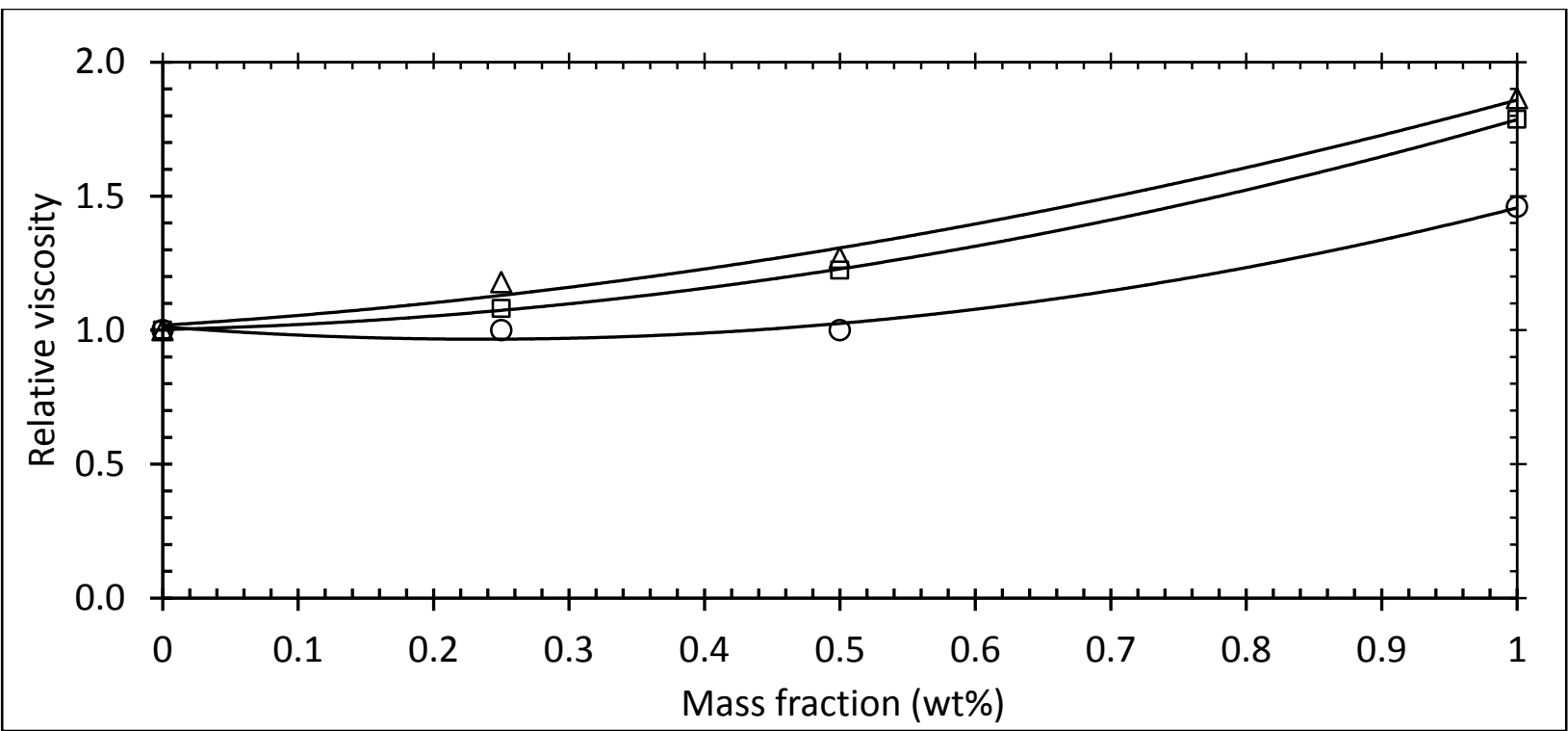

Fig. 11. Increase in ethane viscosity caused by HGA 70-C6 + HGA 65 at $P=20.68 \mathrm{MPa}$ and average shear rate (Equation 2) of $4000-7100 \mathrm{~s}^{-1} . \Delta$ HGA-70 C6 + HGA 65 at $25^{\circ} \mathrm{C}$; $\square$ HGA-70 C6 + HGA 65 at $40^{\circ} \mathrm{C}$; $\circ$ HGA-70 C6 + HGA 65 at $60^{\circ} \mathrm{C}$.

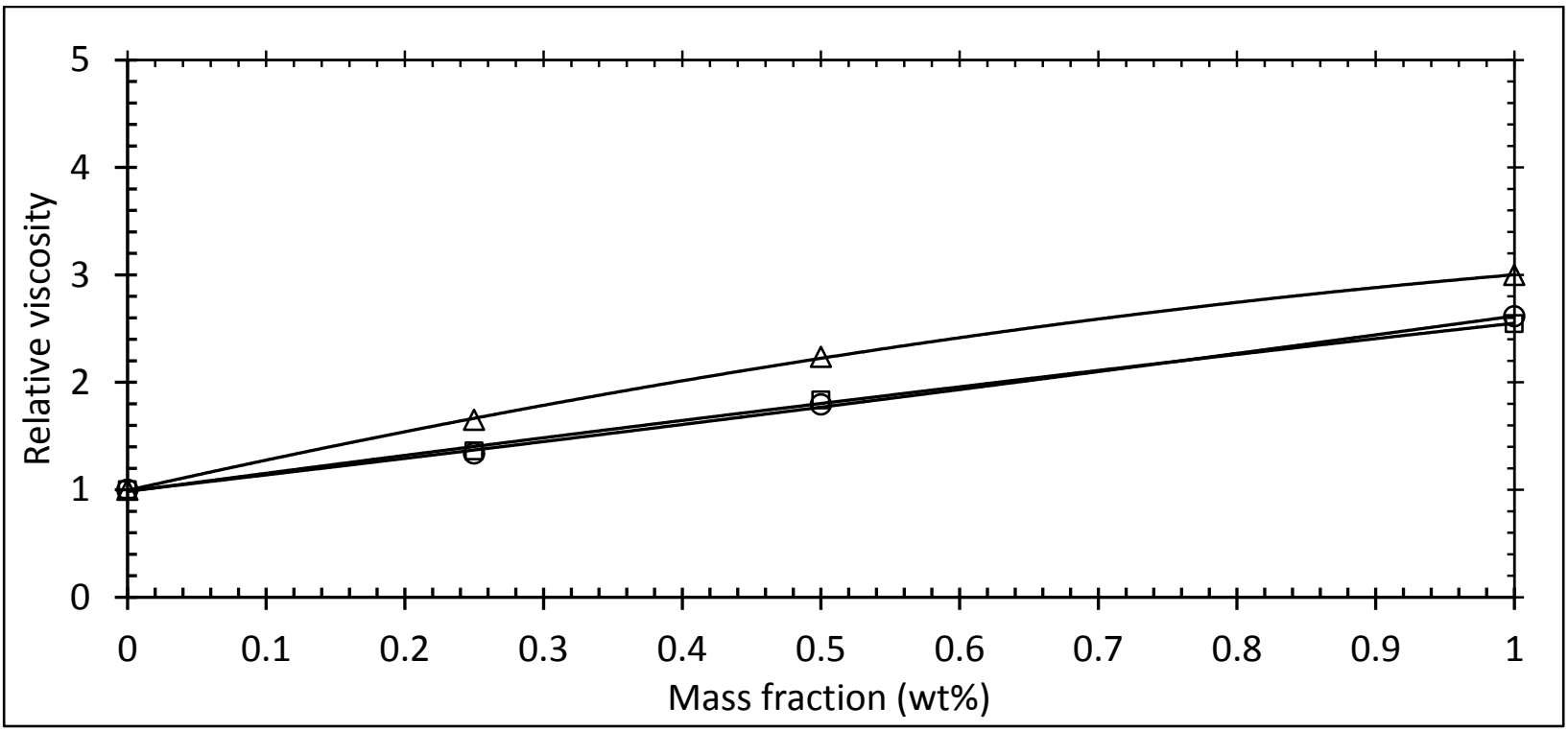

392 Fig. 12. Increase in propane viscosity caused by HGA 70-C6 + HGA 65 at $\mathrm{P}=20.68 \mathrm{MPa}$ and average shear rate 393 (Equation 2) of $2400-7100 \mathrm{~s}^{-1} . \Delta \mathrm{HGA}-70 \mathrm{C} 6+\mathrm{HGA} 65$ at $25^{\circ} \mathrm{C}$; $\square$ HGA-70 C6 + HGA 65 at $40^{\circ} \mathrm{C}$; $\circ \mathrm{HGA}-70$ 394 C6 + HGA 65 at $60^{\circ} \mathrm{C}$. 


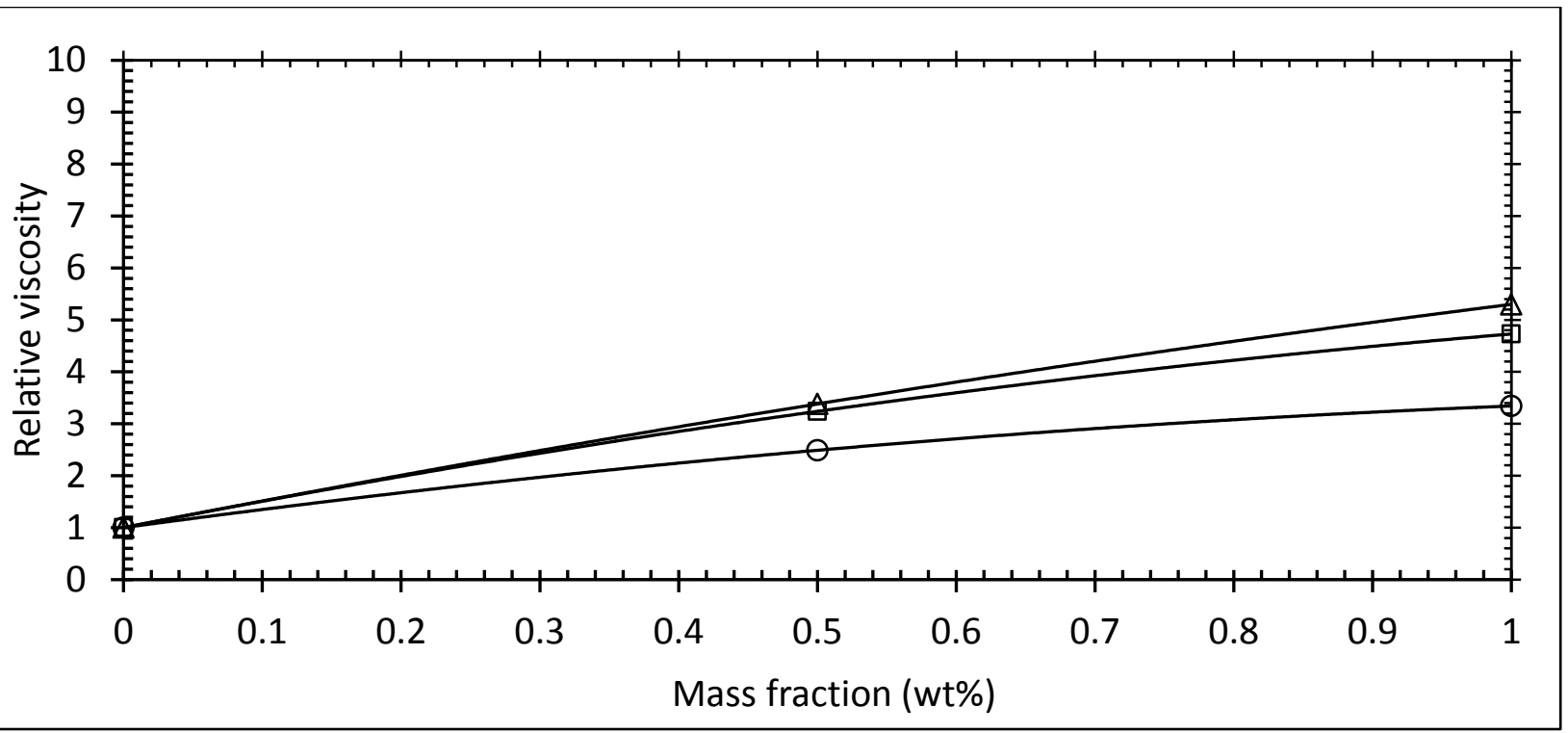

Fig. 13. Increase in butane viscosity caused by HGA 70-C6 + HGA 65 at $\mathrm{P}=20.68 \mathrm{MPa}$ and average shear rate (Equation 2) of $1300-7100 \mathrm{~s}^{-1} . \Delta \mathrm{HGA}-70 \mathrm{C} 6+\mathrm{HGA} 65$ at $25^{\circ} \mathrm{C}$; $\square \mathrm{HGA}-70 \mathrm{C} 6+\mathrm{HGA} 65$ at $40^{\circ} \mathrm{C}$; $\circ \mathrm{HGA}-70$ C6 + HGA 65 at $60^{\circ} \mathrm{C}$.

\section{Conclusions}

Three classes of small molecule thickeners were assessed for their ability to dissolve in high pressure ethane, propane and butane and then to induce viscosity changes at temperatures of 25 to $100^{\circ} \mathrm{C}$. All viscosity measurements were conducted with a close-clearance falling ball viscometer at pressures above the mixture cloud point. In general, increasing pressure resulted in only slight increases in viscosity, while increasing temperature led to decreases in viscosity due to disruption of intermolecular associations.

Tributyltin fluoride (TBTF) is remarkably effective as a viscosity enhancing agent in that it does not require a heating/cooling cycle to attain dissolution. TBTF dissolves readily in these fluids

408 with several minutes of mixing and, at a concentration of $1 \mathrm{wt} \%$, induces nearly 100 -fold 409 viscosity increases at a concentration of $1 \mathrm{wt} \%$ at $25^{\circ} \mathrm{C}$. Although much higher pressures were 410 required to dissolve the TBTF in ethane (than in the other fluids), TBTF induces viscosity 
411 changes in ethane that are comparable to those observed for propane and butane. To the best of

412 our knowledge, this is the first time that a small molecule thickener has ever been reported for

413 ethane.

414 Hydroxyaluminum di-2-ethylhexanoate (HAD2EH) is insoluble in ethane to pressures of $69 \mathrm{MPa}$

415 and temperatures to $100^{\circ} \mathrm{C}$. $\mathrm{HAD} 2 \mathrm{EH}$ does not dissolve in propane or butane unless the high

416 pressure mixture of the alkane and $\mathrm{HAD} 2 \mathrm{EH}$ are first mixed at about $100^{\circ} \mathrm{C}$ and then cooled to

417 the temperature of interest. The solution of HAD2EH in propane or butane remains transparent

418 when the system is cooled to temperature as low as $40^{\circ} \mathrm{C}$; but at $25^{\circ} \mathrm{C}$ the $\mathrm{HAD} 2 \mathrm{EH}$ precipitates.

419 Relative to TBTF, HAD2EH induces a larger viscosity change at comparable composition and

420 temperature. For example, HAD2EH increases the viscosity of liquid propane by a factor of $\sim 10$

421 at a concentration of $1.0 \mathrm{wt} \%$ at $100^{\circ} \mathrm{C}$, while $\mathrm{TBTF}$ at $1 \mathrm{wt} \%$ and a lower temperature of $60^{\circ} \mathrm{C}$

422 increases the viscosity of propane by a factor of only $\sim 6$.

423 A phosphate ester and polyvalent crosslinker combination, LZOS HGA 70-C6 and HGA 65, 424 respectively, exhibits highly desirable attributes for practical application (e.g. low viscosity 425 pump-able liquid components, very fast crosslinking kinetics) and yields substantial viscosity 426 increases for pentane via the formation of an associative phosphate ester network (CPE). 427 However, this two-component mixture did not form a stable, transparent solution in ethane, 428 propane or butane. Rather, a white, translucent fluid formed that contained very fine droplets of 429 a second liquid phase. The "cloud point" for this system is reported as the pressure at which the 430 solution becomes completely opaque upon expansion. Because the ball is able to fall at a 431 terminal velocity through this fluid mixture above the cloud point in a close-clearance falling ball 432 viscometer, relative viscosity can be measured even though the system is not a transparent single 433 phase. At a combined concentration of 1wt\% (HGA 70-C6 phosphate ester + HGA 65 
434 crosslinker), $25^{\circ} \mathrm{C}$ and $20.68 \mathrm{MPa}$, the viscosity of ethane, propane and butane increase by

435 factors of only 1.9, 3.0 and 5.3 at pressures above the cloud point.

\section{Acknowledgment}

437 This work was supported by the U.S. Department of Energy - Advance Research Project 438 Agency-Energy (ARPA-E) (Contract No. DE-AR0000292). The authors are grateful to them for 439 their support. We would also like to express our appreciation to Lubrizol for their enthusiastic 440 support of the newly formed Lubrizol Innovation Collaboration in the Department of Chemical 441 and Petroleum Engineering at the Swanson School of Engineering at the University of 442 Pittsburgh. The authors would like to express their appreciation to Ron Anderson and Scott 443 Schultz of Lubrizol Oilfield Solutions for their provision of the phosphate ester and crosslinker 444 samples and numerous helpful discussions related to gelling hydrocarbon liquids.

$445 \quad$ References

446 [1] L. Koottungal, Survey: Miscible $\mathrm{CO}_{2}$ continues to eclipse steam in US EOR production, $447 \quad$ Oil \& Gas J. 112 (2014) 78.

448 [2] J. J. Taber, Technical screening guides for the enhanced recovery of oil, in: Society of 449 Petroleum Engineers annual Technical Conference and Exhibition, One Petro, California, 450 1983, SPE-12069-MS.

451 [3] D. G. Friend, H. Ingham, J. F. Fly, Thermophysical properties of ethane, J. Physical and 452 Chemical Reference Data 20 (1991) 275-347.

453 [4] H. Miyamoto, K. Watanabe, A thermodynamic property model for fluid-phase propane, 454 International J. Thermophysics 21 (2000) 1045-1072. 
455 [5] H. Miyamoto, K. Watanabe, Thermodynamic property model for fluid-phase n-butane, International J. Thermophysics 22 (2001) 459-475.

457 [6] D. K. Dandge, C. Taylor, J. P. Heller, K. V. Wilson, N. Brumley, Associative organotin 458

[7] R. M. Enick, The effect of hydroxy aluminum disoaps on the viscosity of light alkanes

[8] K. W. Smith, L. J. Persinski, US Patent 5614010 A, 1997.

464 [9] R. S. Taylor, G. P. Funkhouser, US Patent 7314850 B2, 2008.

[10] P. Dunn, D. Oldfield, Tri-normal-butyltin fluoride - a novel coordination polymer in 
476 [15] M. Hughes, Napalm: an american biography, War in History 21 (2014) 560-562.

477 [16] K. Mysels, Napalm - mixture of aluminum disoaps, Industrial \& Engineering Chemistry $478 \quad$ Research 41 (1949) 1435-1438.

479 [17] N. Pilpel, Properties of organic solutions of heavy metal soaps, Chemical Reviews 63 $480 \quad$ (1963) 221-234.

481 [18] K. W. Smith, L. J. Persinski, US Patent 5417287 A, 1995.

482 [19] K. W. Smith, L. J. Persinski, US Patent 5571315 A, 1996.

483 [20] R. S. Taylor, G. P. Funkhouser, US Patent 6511944 B2, 2003.

484 [21] R. S. Taylor, G. P. Funkhouser, R. G. Dusterhoft, R. S. Lestz, A. Byrd, US Patent $485 \quad 7,341,103 \mathrm{~B} 2,2008$.

486 [22] E. Delgado, B. Keown, US Patent 8377854 B2, 2013.

487 [23] R. Taylor, A. Khallad, A. Cheng, B. Barree, J. Byrnes, K. Kelly, M. Conway, R. 488 Caufield, S. Tourigny, Optimized gas-well stimulating using $\mathrm{CO}_{2}$-miscible, viscosified 489 490 491 492

[25] G. P. Funkhouser, N. Tonmukayakul, F. Liang, Rheological comparison of 494 organogelators based on iron and aluminum complexes of dodecylmethylphosphinic acid 495 and methyl dodecanephosphonic acid, Langmuir 25 (2009) 8672-8677. 
496 [26] M. George, G. P. Funkhouser, P. Terech, R. G. Weiss, Organogels with Fe(III) complexes of phosphorus-containing amphiphiles as two-component isothermal gelators, Langmuir 22 (2006) 7885-7893.

499

500

501

502

503

504

505

506

507

508

509

510

511

512

513

514

515

516

[27] M. George, G. P. Funkhouser, R. G. Weiss, Organogels with complexes of ions and phosphorus-containing amphiphiles as gelators. Spontaneous gelation by in situ complexation, Langmuir 24 (2008) 3537-3544.

[28] M. G. Page, G. G. Warr, Influence of the structure and composition of mono- and dialkyl phosphate mixtures on aluminum complex organogels, Langmuir 25 (2009) 8810-8816.

[29] R. E. Hurst, Use of liquified gases as fracture fluids for dry gas reservoirs, in: Society of Petroleum Engineers of AIME, Texas, 1972, SPE-4116-MS.

[30] C. F. Smith, Gas well fracturing using gelled non-aqueous fluids, in: Society of Petroleum Engineers of AIME, Nevada, 1973, SPE-4678-MS.

[31] R. S. Taylor, R. S. Lestz, L. Wilson, G. P. Funkhouser, H. Watkins, D. Attaway, Liquid petroleum gas fracturing fluids for unconventional gas reservoirs, in: Canadian International Petroleum Conference, Alberta, 2006, paper 2006-169.

[32] E. H. Tudor, G. W. Nevison, S. Allen, B. Pike, 100\% gelled LPG fracturing process: an alternative to conventional water-based fracturing techniques, in: Society of Petroleum Engineers regional meeting, West Virginia, 2009, SPE-124495-MS.

[33] R. S. Lestz, L. Wilson, R. S. Taylor, G. P. Funkhouser, H. Watkins, D. Attaway, Liquid petroleum gas fracturing fluids for unconventional gas reservoirs, J. Canadian Petroleum Technology 46 (2007) 68-72. 
517 [34] R. S. Taylor, R. S. Lestz, D. B. Bennion, G. P. Funkhouser, I. R. Geddes, Rheological evaluations of co miscible hydrocarbon fracturing fluids, J. Canadian Petroleum Technology 44 (2005) 65-69.

520

521

522

523

524

525

526

527

528

529

530

531

532

533

534

535

536

[35] A. Dhuwe, J. Sullivan, J. Lee, A. Klara, S. Cummings, R. Enick, E. Beckman, and R. Perry, Close-clearance high pressure falling ball viscometer assessment of ultra-high molecular weight polymeric thickeners for ethane, propane and butane, J. Petroleum Science and Engineering (2016) submitted.

[36] L. Hong, E. Fidler, R. Enick, R. Marentis, Tri-tert-butylphenol: a highly $\mathrm{CO}_{2}$-soluble sand binder, J. Supercritical Fluids 44 (2008) 1-7.

[37] S. Kilic, S. Michalik, Y. Wang, J. K. Johnson, R. M. Enick, E. J. Beckman, Effect of grafted lewis base groups on the phase behavior of model poly(dimethyl siloxanes) in $\mathrm{CO}_{2}$, Industrial \& Engineering Chemistry Research 42 (2003) 6415-6424.

[38] M. B. Miller, D.-L. Chen, H.-B. Xie, D. R. Luebke, J. Karl Johnson, R. M. Enick, Solubility of $\mathrm{CO}_{2}$ in $\mathrm{CO}_{2}$-philic oligomers; Cosmotherm predictions and experimental results, Fluid Phase Equilibria 287 (2009) 26-32.

[39] Z. H. Huang, C. M. Shi, J. H. Xu, S. Kilic, R. M. Enick, E. J. Beckman, Enhancement of the viscosity of carbon dioxide using styrene/fluoroacrylate copolymers, Macromolecules 33 (2000) 5437-5442.

[40] J. Xu, A. Wlaschin, R. M. Enick, "Thickening carbon dioxide with the fluoroacrylatestyrene copolymer, Society of Petroleum Engineers J. 8 (2003) 85-91. 
537 [41] A. Dhuwe, Thickeners for natural gas liquids to improve the performance in enhanced oil recovery and fracturing, M.S. thesis, University of Pittsburgh, 2016.

539 [42] C. M. Hansen, Hansen solubility parameters: a user's handbook, 2nd ed., CRC, Florida, 540 2007, pp. 347-485. 

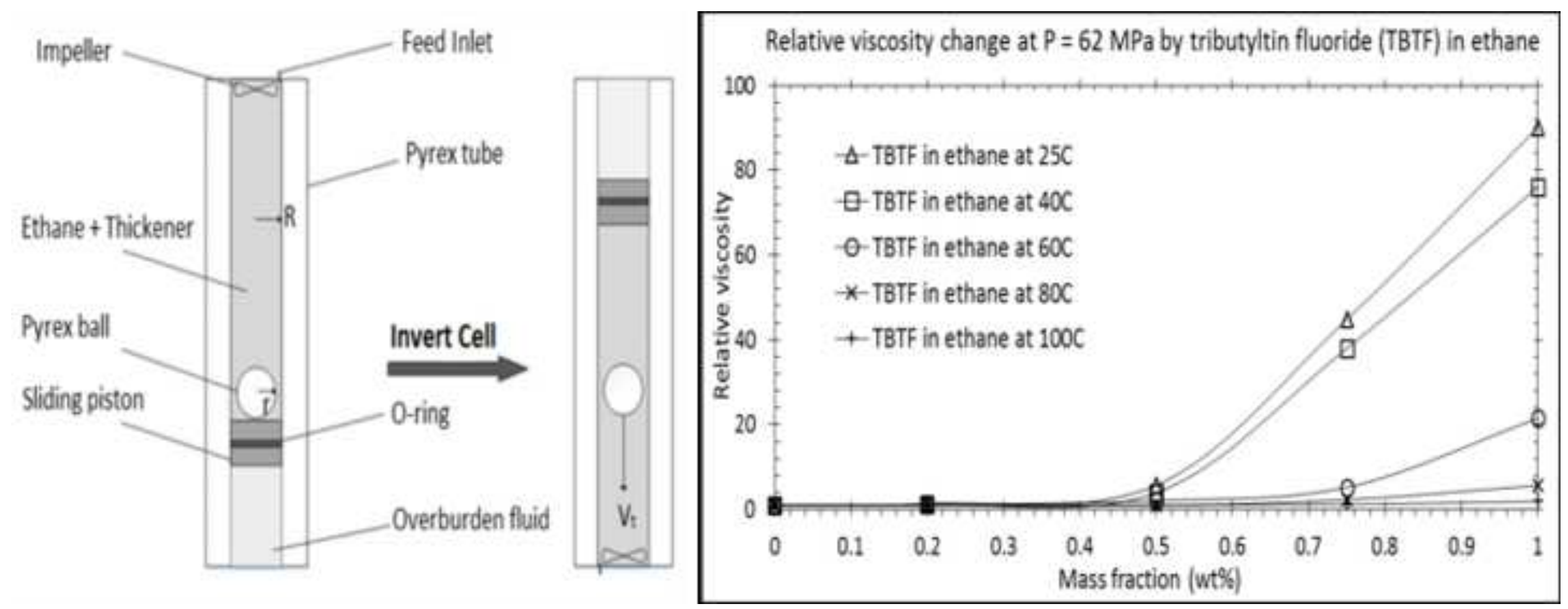